\title{
Photocatalytic degradation of Phenol, Catechol and Hydroquinone over Au-ZnO nanomaterials
}

\author{
Degradación fotocatalítica de Fenol, Catecol e Hidroquinona sobre nanomateriales Au-Zn0
}

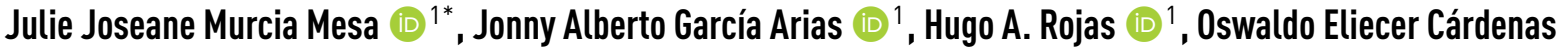 Espinosa $\mathbb{1}^{2}$}

${ }^{1}$ Grupo de Catálisis, Escuela de Ciencias Químicas, Universidad Pedagógica y Tecnológica de Colombia UPTC. Avenida Central del Norte. C. P. 150001. Tunja, Colombia.

${ }^{2}$ Grupo de Química-física molecular y modelamiento computacional QUIMOL, Escuela de Ciencias Químicas, Universidad Pedagógica y Tecnológica de Colombia UPTC. Avenida Central del Norte. C. P. 150001. Tunja, Colombia.

\section{CITE THIS ARTICLE AS:}

J. J. Murcia, J. A. García, H.

A. Rojas and O. E.

Cárdenas. "Photocatalytic degradation of Phenol, Catechol and Hydroquinone over Au-ZnO

nanomaterials", Revista

Facultad de Ingeniería

Universidad de Antioquia, no.

94, pp. 24-32, Jan-Mar

2020. [Online]. Available:

https : //www.doi.org/

10.17533/udea.redin.

20190513

\section{ARTICLE INFO:}

Received: December 04, 2018

Accepted: May 09, 2019

Available online: May 10, 2019

\section{KEYWORDS:}

Phenolic compounds; photocatalysis; Au-ZnO

Compuestos fenólicos; fotocatálisis; Au-ZnO
ABSTRACT: Au-ZnO nanomaterials were tested in photodegradation reactions performed under UV-Visible light; Phenol, Catechol and Hydroquinone were selected as target molecules, and it was found that Hydroquinone is the most sensitive molecule to be degraded under illumination. The Au addition significantly increases the photocatalytic activity of $\mathrm{ZnO}$ in the degradation of the phenolic compounds and the Au content is an important factor influencing the physicochemical properties of the nanomaterials synthesized and therefore the effectiveness of the photocatalytic treatment. The highest effectiveness in the phenolic compounds elimination was achieved by using $\mathrm{ZnO}$ modified by the addition of 2 wt.\% of gold, this is due to the highest absorption of this material in the visible region of the electromagnetic spectrum. By HPLC analyzes, it was determined that the degradation route of the phenolic compounds depends on the photocatalyst employed in the catalytic reaction and on the substrate to be degraded, thus, Phenol degradation takes place by formation of more intermediate compounds than the observed in Catechol or Hydroquinone photodegradation.

RESUMEN: Algunos nanomateriales tipo $\mathrm{Au}-\mathrm{ZnO}$ fueron evaluados en reacciones de fotodegradación bajo luz UV-Visible; Fenol, Catecol e hidroquinona fueron las moléculas modelo, en general se encontró que la Hidroquinona es la molécula más sensible a la degradación bajo iluminación. La adición de Au incrementa significativamente la actividad fotocatalítica del $\mathrm{ZnO}$ en la degradación de los compuestos fenólicos y el contenido de $\mathrm{Au}$ es un factor con una influencia muy importante sobre las propiedades físicoquímicas de los nanomateriales sintetizados y sobre la efectividad del tratamiento fotocatalítico. La efectividad más alta en la eliminación de los compuestos fenólicos se logró usando ZnO modificado por adición de $2 \%$ en peso de oro, esto se debe a la mayor absorción que presenta este material en la región visible del espectro electromagético. Por HPLC, se encontró que la ruta de degradación de los compuestos fenólicos depende del fotocatalizador empleado en la reacción y del sustrato a degradar, así, la degradación del Fenol se lleva a cabo a través de la formación de un mayor número de compuestos intermediarios que lo observado en la degradación de Catecol e Hidroquinona.

\section{Introduction}

Industrial effluents commonly contain high levels of organic pollutants such as phenolic compounds, the acute toxicity of these compounds has been extensively studied,

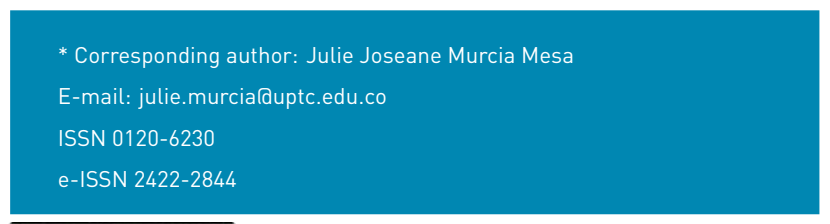

and 11 phenolic compounds have been classified as priority pollutants by the US Environmental Protection Agency (EPA). Phenolic compounds are known to be biorecalcitrants and to produce undesired organoleptic properties in water; in addition, these compounds have been associated with different illnesses such as cancer. Different authors have analyzed and employed many alternatives to remove phenolic compounds from water sources [1-6]. 
The phenolic compounds selected for the present study are widely employed in industry, firstly, Phenol, is used as disinfectant and in the production of polymeric resins such as Baquelite; Phenol is one of the most persistent aromatic compounds frequently found in industrial wastewater, representing a serious problem for the environment $[7,8]$. In addition, during the Phenol degradation, it is possible to obtain different intermediates mainly represented by Catechol, Hydroquinone, $\mathrm{p}$-Benzoquinone and short chain organic acids [9]. Hydroquinone 11,4-dihidroxibencene, $\mathrm{HQ}$ ) and Catechol (1,2-dihidroxibencene, CT) are positional isomers of phenolic compounds, Hydroquinone is used in cosmetics, in the treatment of skin pathologies and in photography [10]. On the other hand, Catechol is an intermediary compound in pharmaceutics industry and in the production of agrochemicals; in addition, Catechol is an important precursor in the production of flavors such as Vanillin and Eugenol, which are widely employed in food industry and in the production of fragrances and cleaning products [11].

The treatment of water sources polluted with phenolic compounds has been a big technology challenge; it is because in many cases the conventional treatments are not totally efficient, for that reason in the last decades the development of alternative environmental remediation processes has fast evolution; thus, heterogeneous photocatalysis, currently represents a suitable alternative in the treatment of phenolic compounds in liquid phase. Photocatalytic treatment involves the irradiation of a solid semiconductor by UV-Visible light, as a result of this irradiation and the presence of an oxidant agent, $\bullet \mathrm{OH}$ radicals are generated by redox reactions which occur on the photocatalyst surface $[1-8,12]$.

Titanium dioxide has been mainly employed as a photocatalyst in the photodegradation of phenolic compounds; however, Zinc oxide also has special attention in the last years as an alternative to $\mathrm{TiO}_{2}$, thus, $\mathrm{ZnO}$ has been successfully employed in the total mineralization of organic pollutants $[13,14]$. The properties of these semiconductors are very similar, thus, both of them are active under UV light, the band gap value corresponds to $3.2 \mathrm{eV}$ and $3.3 \mathrm{eV}$ for $\mathrm{TiO}_{2}$ and $\mathrm{ZnO}$, respectively. However, one of the main disadvantages of $\mathrm{TiO}_{2}$ is that this semiconductor only presents absorption in the UV region, compared with their counterpart the $\mathrm{ZnO}$ which presents oxygen vacancies as surface defects, these defects lead to obtain high optic transmission in the visible region of the electromagnetic spectrum [15]. It is important to take into account that $\mathrm{ZnO}$ is unsuitable to use as photocatalyst in reaction medium with low $\mathrm{pH}$ values, it is because this solid can be soluble at low pH [16].
In the present work, it was evaluated the effectiveness of $\mathrm{ZnO}$ photocatalyst modified by gold addition in the photodegradation of Phenol, Catechol and Hydroquinone; samples containing a mix of these compounds were also prepared and the evaluation of the reaction mechanism was also attempted.

\section{Experimental section}

\subsection{Synthesis of Au-Zno photocatalytic materials}

Commercial Zinc oxide provided by Riedel de Haen was used as received, Au-ZnO materials were obtained by photodeposition method using tetrachloroauric acid (III) $\left(\mathrm{HAuCl}_{4}\right)$ provided by Aldrich with $99.9 \%$ of purity, as gold precursor. Two series of samples with different Au content (i.e 0.5 and 2 wt.\%) were prepared. Firstly, a suspension containing commercial $\mathrm{ZnO}$, isopropanol (electrons donor) provided by Merck with $99.9 \%$ of purity and the metal precursor was prepared. The suspension was illuminated during $120 \mathrm{~min}$ under $\mathrm{N}_{2}$ atmosphere with constant stirring. An Osram ultra-vitalux lamp (300 W) was used as the light source, the illumination intensity was measured by using a Delta OHM HD 2102.1 photoradiometer, being 40 $\mathrm{W} / \mathrm{m}^{2}$. The obtained powders $10.5 \mathrm{wt}$. $\% \mathrm{Au}-\mathrm{ZnO}$ and $2 \mathrm{wt} . \%$ $\mathrm{Au}-\mathrm{ZnO}$ ) were recovered by filtration, washing and drying at $120{ }^{\circ} \mathrm{C}$ for 12 hours. Commercial $\mathrm{TiO}_{2} \mathrm{P} 25$ Evonik was used as received and employed as the reference material.

\subsection{Au-ZnO photocatalysts characterization}

All the photocatalytic materials were analyzed by X-ray diffraction (XRD), X-ray fluorescence (XRF), Scanning Electron Microscopy (SEM), $\mathrm{N}_{2}$ Physisorption $\left(\mathrm{S}_{\mathrm{BET}}\right)$, Fourier Transformation Infrared Spectroscopy (FTIR) and UV-Vis Diffuse Reflectance (UV-Vis DRS). The analysis conditions employed are summarized as follows:

The composition of the crystalline phases was determined by XRD, this analysis was carried out by using XPERT Pro Panalytical equipment and $\mathrm{Cu} \mathrm{K} \alpha$ radiation, a continuous scanning was carried out with a $2 \theta$ angle between $20^{\circ}$ and $80^{\circ}$, an 80 seconds step was employed.

Chemical composition determination was carried out by XRF; a Panalytical Minipal 2 equipment was employed, for these analyzes $\mathrm{He}, 20 \mathrm{KV}$ and 180 seconds were used as experimental parameters.

In order to observe the morphology and gold particles dispersion on ZnO surface, SEM analyzes were performed by using an EVO MA10 Zeiss microscope. 
Specific surface area measurements were carried out by low-temperature $\mathrm{N}_{2}$ adsorption in a Micromeritics ASAP 2020 instrument. Degasification of the samples was performed at $150{ }^{\circ} \mathrm{C}$. The functional groups present in the samples were analyzed by FTIR, a Thermo Scientific Nicolet TM iSTM 50 FT-IR spectrophotometer was used, all the samples were analyzed in a wavenumber between 4000 and $1000 \mathrm{~cm}^{-1}$, for these analyzes the samples were dried at $120^{\circ} \mathrm{C}$ for $12 \mathrm{~h}$ and then prepared in a $\mathrm{KBr}$ tablet.

Light absorption properties of the samples were studied by UV-Vis spectrophotometry. The UV-vis DR spectra were recorded on a UV-2600 SHIMADZU spectrophotometer equipped with an ISR-2600 integrating sphere. Band-gaps values were calculated from the corresponding Kubelka-Munk functions, $F(R \infty)$, which are proportional to the absorption of radiation by plotting $F(R \propto \times h \nu)^{1 / 2}$ against h $\nu$.

\subsection{Phenolic compounds photodegradation tests}

Photocatalytic tests were performed by using $25 \mathrm{ppm}$ solutions of Phenol, Catechol or Hydroquinone provided by Aldrich and $1 \mathrm{~g} / \mathrm{L}$ of photocatalyst suspended in the liquid phase; each photoreaction was followed by a total time of $120 \mathrm{~min}$ under continuous stirring, $120 \mathrm{~W} / \mathrm{m}^{2}$ of light intensity was provided by an UV-Visible Osram Ultravitalux lamp. In order to favor the adsorption-desorption equilibrium, the phenolic compounds solutions were mantained in dark during $10 \mathrm{~min}$ before switching on the lamp. Photolysis experiments without photocatalyst were also carried out.

The phenolic compounds identification during the photocatalytic reactions was performed by High Performance Liquid Chromatography (HPLC), a Shimadzu LC - 2030 chromatograph equipped with an UV-Vis detector and a column MACHEREY-NAGEL C18 $1150 \mathrm{~mm}$, $5 \mathrm{~mm} \times 5 \mu \mathrm{m})$. The experimental conditions employed in these analyzes are described as follows: injection volume $10 \mu \mathrm{L}$, the mobile phase was composed by water: methanol (provided by Merck with $99.5 \%$ of purity) with a $65: 35$ ratio, $1.3 \mathrm{~mL} / \mathrm{min}$ of flux, total run time of $5 \mathrm{~min}$ and $40^{\circ} \mathrm{C}$ of temperature.

An Analytikjena Multi N/C 2100 equipment was employed for Total Organic Carbon (TOC) analysis, for this analysis $100, \mu \mathrm{L}$ of filtered samples were measured, by using a furnace temperature of $750{ }^{\circ} \mathrm{C}$. Three measurements were performed for each sample and the average value was considered.

\section{Results and discussion}

\subsection{Photocatalysts characterization}

Figure 1 shows the XRD patterns for the Zinc Oxide modified photocatalysts, by this technique it was possible to identify the diffraction peaks (100), (002), (101), (102), (110), (103), (200), (112) and (201) these peaks are located in the $2 \theta$ positions of $37.26^{\circ}, 40.40^{\circ}, 42.56^{\circ}, 56.04^{\circ}$, $67.05^{\circ}, 74.78^{\circ}$ and $79.17^{\circ}$, respectively [17]. These peaks correspond to the hexagonal Wurtzite, the crystalline form characteristic of $\mathrm{ZnO}$. It was also possible to determine that the photodeposition of $0.5 \mathrm{wt} \% \mathrm{Au}$ on $\mathrm{ZnO}$ surface did not modify the XRD patterns; it can be mainly due to the low content and size of the gold nanoparticles in this material; however, in the photocatalyst prepared with the highest gold content ( $2 \mathrm{wt} \% \mathrm{Au}-\mathrm{ZnO}$ ), it is evident the presence of a diffraction peak characteristic of the metallic gold, located at $44.72^{\circ}$, as it is indicated in Figure 1.

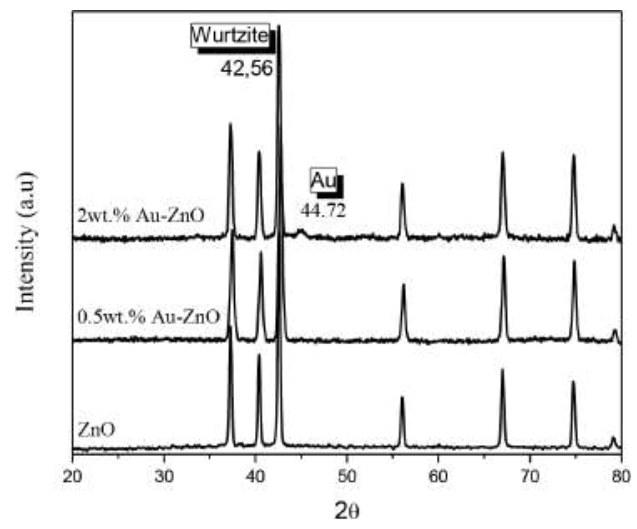

Figure $1 \mathrm{XDR}$ patterns for the $\mathrm{ZnO}$ modified photocatalysts

It was observed that the real gold content increases with the nominal content used in the synthesis of the photocatalysts prepared; low content of chloride remaining from the gold precursor was also detected in the samples by XRF.

In order to analyze the morphology and gold particles size in the photocatalysts prepared, SEM analyzes were carried out and a selected micrographs of $0.5 \mathrm{wt} \%$ and $2 \mathrm{wt} . \%$ $\mathrm{Au}-\mathrm{ZnO}$ photocatalysts are presented in Figure 2. As it can be observed in these images, the Au nanoparticles are heterogeneously distributed on $\mathrm{ZnO}$ surface. It has been also observed that when the gold content increases the Au particle size also increases, thus, in the $2 \mathrm{wt} \% \mathrm{Au}-\mathrm{ZnO}$ photocatalyst, were observed Au particle sizes close to $100 \mathrm{~nm}$.

Specific surface area was found to be 5.66, 2.89 and $3.69 \mathrm{~m}^{2} / \mathrm{g}$ for $\mathrm{ZnO}, 0.5$ wt. $\% \mathrm{Au}-\mathrm{ZnO}$ and $2 \mathrm{wt} . \% \mathrm{Au}-\mathrm{ZnO}$ 

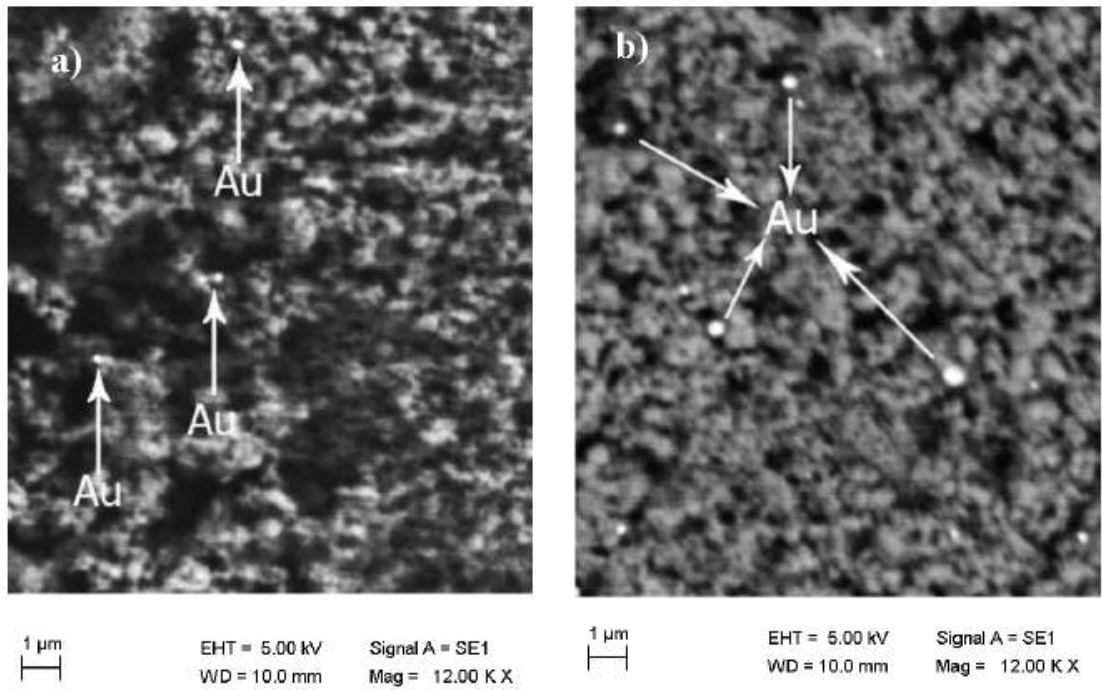

WD $=10.0 \mathrm{~mm} \quad \mathrm{Mag}=12.00 \mathrm{KX}$

Figure 2 SEM images of (a) 0.5 wt. $\%$ and (b) 2 wt.\% Au-ZnO photocatalysts

photocatalysts, respectively.

As it can be observed, the $\mathrm{S}_{\mathrm{BET}}$ value decreases after $\mathrm{Au}$ photodeposition, it is due to the presence of $\mathrm{Au}$ nanoparticles which causes obstruction of the $\mathrm{ZnO}$ pores; however, in the photocatalyst modified by the addition of $2 \mathrm{wt} . \%$ of gold, it is observed a slight increase in the specific surface area, this is due to the higher size of the $\mathrm{Au}$ particles present in this material compared with 0.5 wt.\% Au-ZnO sample as it was observed by SEM analyzes (Figure 2), thus, the aggregation of gold particles of high size, leads to obtain the lowest number of $A u$ particles over $\mathrm{ZnO}$ surface, thus leading to less surface obstruction.

Figure 3 shows the FTIR spectra obtained for the photocatalysts analyzed, in the $\mathrm{ZnO}$ spectrum it is possible to identify a wide band located at $3,408 \mathrm{~cm}^{-1}$, which corresponds to hydroxyl groups; the bands observed in the region between $1,558 \mathrm{~cm}^{-1}$ and $1386 \mathrm{~cm}^{-1}$ correspond to $\mathrm{H}-\mathrm{O}-\mathrm{H}$ flexion vibration signals, these bands indicate the presence of water linked to the $\mathrm{ZnO}$ structure $[18,19]$. By FTIR, it was also observed that the intensity of the bands located between 2,500 and $3,000 \mathrm{~cm}^{-1}$ and between 1,000 and $2,000 \mathrm{~cm}^{-1}$ slightly decreases after gold photodeposition, it is most evident in the photocatalyst prepared with $0.5 \mathrm{wt} . \%$ of Au compared with the material prepared with 2 wt.\%, it is mainly due to the higher number of Au nanoparticles present in the catalysts 0.5 wt.\% Au-ZnO compared with their counterpart 2 wt.\% $\mathrm{Au}-\mathrm{ZnO}$, thus, the gold nanoparticles can reduce the starting surface hydroxylation of $\mathrm{ZnO}$, this effect is less evident when the gold content increases, it is because, the photocatalyst prepared with $2 \mathrm{wt}$ \% of gold shows the highest particles size, as it can be observed by the SEM analyzes presented in the previous section (Figure 2).

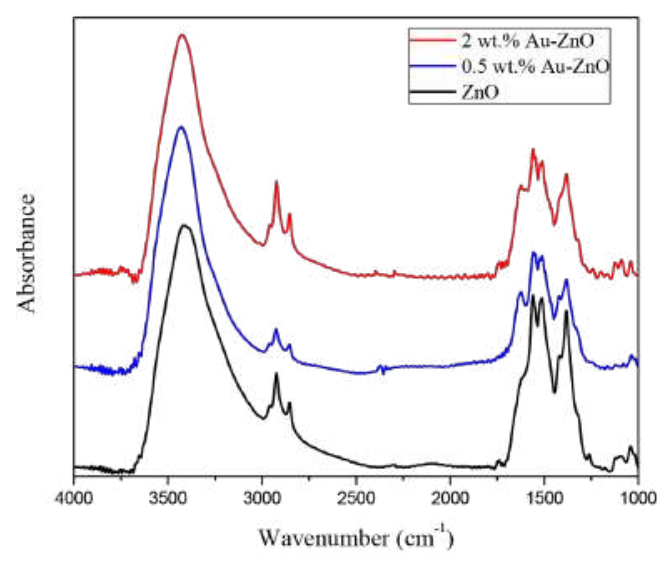

Figure 3 FTIR spectra for the photocatalysts analyzed

UV-Vis DR spectra for the photocatalysts analyzed are presented in Figure 4.

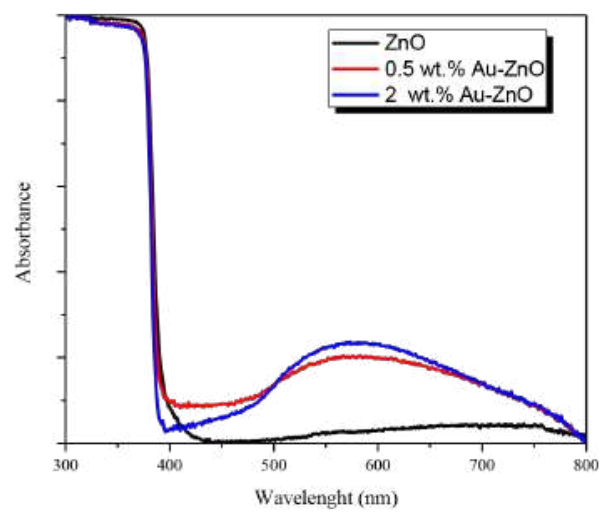

Figure 4 UV-Vis DR spectra for the photocatalysts analyzed 
From UV-Vis DRS analysis, it was possible to observe that the gold addition on ZnO surface improves the absorption of this semiconductor in the visible region of the electromagnetic spectrum, thus after gold addition a high absorption was observed in the region between 400 and $800 \mathrm{~nm}$, it is mainly due to the purple color of the metallized $\mathrm{ZnO}$; thus in this region the gold plasmon located at $576 \mathrm{~nm}$ is clearly observed (Figure 4). The highest intensity and therefore the highest absorption was observed in the band ascribed to the gold plasmon in the photocatalyst prepared with 2 wt.\% of gold as it can be seen in Figure 4. The band gap values of the photocatalysts were also calculated from UV-Vis DRS analyzes, these values were found to be close to $3.3 \mathrm{eV}$, and any significant modification in the band gap value of $\mathrm{ZnO}$ was observed after gold addition.

\subsection{Phenolic compounds photodegradation}

Photolysis experiments for each phenolic compound without catalyst and under UV-Visible light were carried out as the blank test; the results obtained are represented in Figure 5. As it can be seen in this figure, the photolysis phenomenon is negligible in the case of Phenol and Catechol; however, Hydroquinone is very susceptible to be degraded under illumination, thus, the Hydroquinone concentration highly decreases by photolysis from 25 to 7 ppm. Taking into account these results, it is expected that this compound presents the highest degradation rate during the photocatalytic reactions.

After photolysis tests, the effectiveness of the photocatalysts prepared was evaluated in the Phenol, Catechol and Hydroquinone photodegradation, the results obtained for each phenolic compound in these analyzes are described as follows.

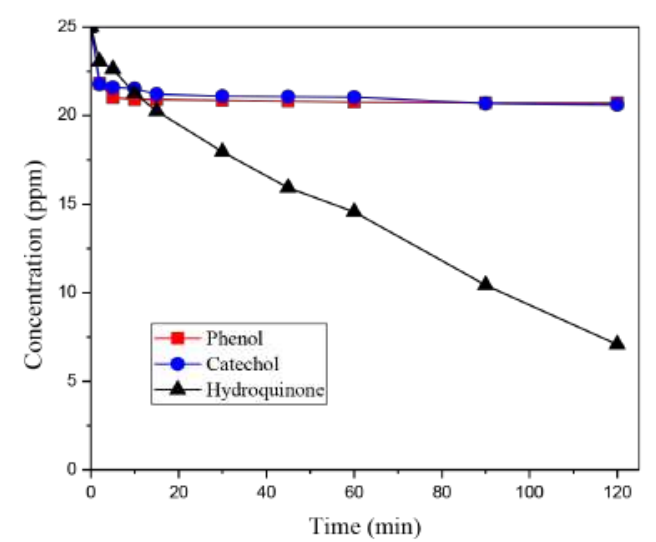

Figure 5 Photolysis tests for phenolic compounds under UV-Visible light

\section{Phenol photodegradation}

Figure 6 shows the HPLC signals identified after five minutes of Phenol photodegradation by using $\mathrm{ZnO}$ as photocatalyst. In this figure, it is possible to clearly identify 4 signals, thus indicating that phenol can be transformed into three new compounds during reaction, these compounds were identified as Catechol (retention time $0.5 \mathrm{~min}$ ), Hydroquinone (retention time $0.98 \mathrm{~min}$ ), at the retention time of 1.26 minutes was detected an unidentified intermediate compound, this signal is probably due to the formation of Resorcinol or a short chain organic acid, as it was indicated by different authors [20-23]; finally, the phenol signal is located at 1.77 minutes.

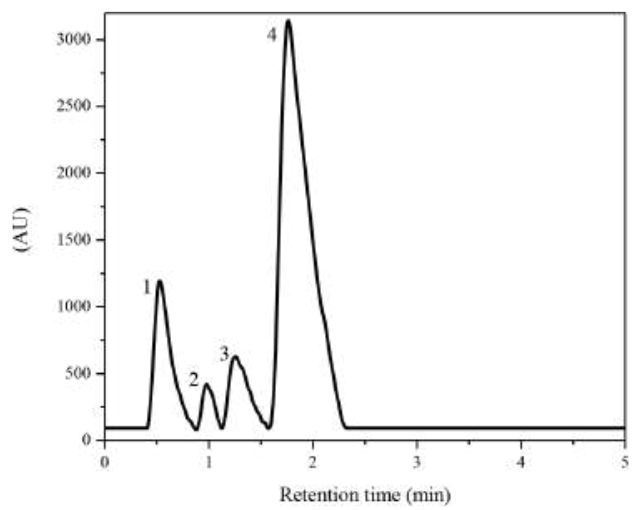

Figure 6 HPLC signals identified for Phenol photodegradation over ZnO. (1) Catechol; (2) Hydroquinone; (3) other intermediate and (4) Phenol

For comparison purposes, the evolution of phenol transformation during photocatalytic reaction over $\mathrm{ZnO}$ is represented in Figure 7, as it can be seen according to HPLC results, after 15 minutes of reaction only Catechol and Hydroquinone remained in the reaction medium, then, the phenol transformation continues until 120 minutes of photoreaction when the total phenolic compounds elimination was achieved; however by TOC analyzes, it was possible to determine that in fact, the total organic carbon decreases as the photoreaction time increases, but at the end of $120 \mathrm{~min}$ of reaction almost $10 \mathrm{mg} / \mathrm{L}$ of TOC was still detected, thus indicating that the total phenolic compounds mineralization was not achieved under the reaction conditions used in the present work. Additional analyzes lead to observe that by increasing the reaction time the TOC values significantly decreases.

The phenol concentration was calculated in each step of reaction and the results are shown in Figure 8 , this figure presents the evolution of the pollutant concentration as a function of photoreaction time over the $\mathrm{ZnO}$ modified photocatalysts analyzed. 


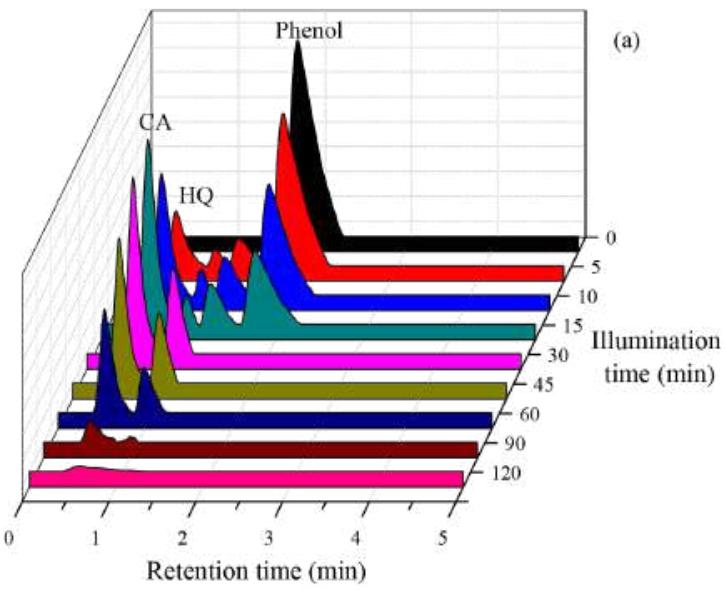

Figure 7 Evolution of phenol transformation during the photocatalytic reaction over $\mathrm{ZnO}$

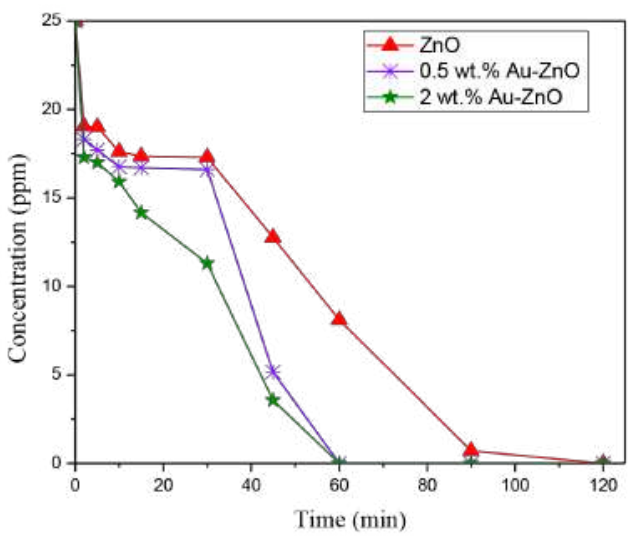

Figure 8 Evolution of the Phenol concentration after photocatalytic reaction by using the materials analyzed

As it can be observed in Figure 8, the Phenol concentration significantly decreases under UV-Visible light and in presence of a photocatalyst compared with the results observed in the photolysis tests previously presented. It is also observed that the Au addition on $\mathrm{ZnO}$ surface, significantly improves the photocatalytic efficiency of this semiconductor in the Phenol photodegradation; thus, the total Phenol degradation was achieved in half the time with Au-ZnO compared with bare $\mathrm{ZnO}$. In 60 minutes of photoreaction, no Phenol was detected in the liquid phase by using 0.5 or $2 \mathrm{wt} . \% \mathrm{Au}-\mathrm{ZnO}$; however, the highest reaction rate in the phenol degradation was achieved by using the photocatalyst prepared with $2 \mathrm{wt}$. $\%$ of gold (i.e $6.9 \times 10^{-3} \mathrm{mg}$ of Phenol. L ${ }^{-1} . \mathrm{s}^{-1}$ ).

It is widely known that the noble metal doping of $\mathrm{ZnO}$ leads to improve the photocatalytic efficiency of this semiconductor $[13,24]$, this is because the noble metal nanoparticles act as a sink for the electrons generated during the photocatalytic reaction, thus avoiding the electron - hole recombination, and therefore increasing the half life time of the photogenerated charges. In addition, the gold nanoparticles addition modifies the $\mathrm{ZnO}$ color; starting $\mathrm{ZnO}$ present a white color and after gold addition a purple color is observed, this color change leads to increase the absorption of this oxide in the visible region of the electromagnetic spectrum as it was observed by UV-Vis DRS analyzes (Figure 4).

The positive effects of the gold nanoparticles in the photocatalytic processes, above described, can explain the results observed in the phenol photodegradation over $\mathrm{Au}-\mathrm{ZnO}$ materials. On the other hand, the highest photoactivity observed with the 2 wt.\% Au-ZnO photocatalyst, may be due to the lower number of gold nanoparticles on $\mathrm{ZnO}$ surface compared with their counterpart the photocatalyst prepared with $0.5 \mathrm{wt} . \%$ of $\mathrm{Au}$, as it can be observed by SEM analyzes (Figure 2), which led to a lower obstruction on $\mathrm{ZnO}$ surface as it was observed by $\mathrm{S}_{\mathrm{BET}}$ and FTIR results previously discussed.

\section{Catechol photodegradation}

By HPLC, it was possible to observe that during the photocatalytic reactions carried out by using $\mathrm{Au}-\mathrm{ZnO}$ materials, Catechol is transformed only into Hydroquinone (for the sake of brevity the chromatograms obtained are not included). It was also observed that the Catechol photodegradation increases by using the photocatalyst modified by gold addition, similar to the behavior observed in the Phenol degradation tests; however, in the case of the Catechol there is not an important difference in the results obtained with the photocatalyst prepared with 0.5 or $2 \mathrm{wt} . \%$, in this case total Catechol mineralization was achieved after $45 \mathrm{~min}$ of photocatalytic reaction as it can be seen in Figure 9.

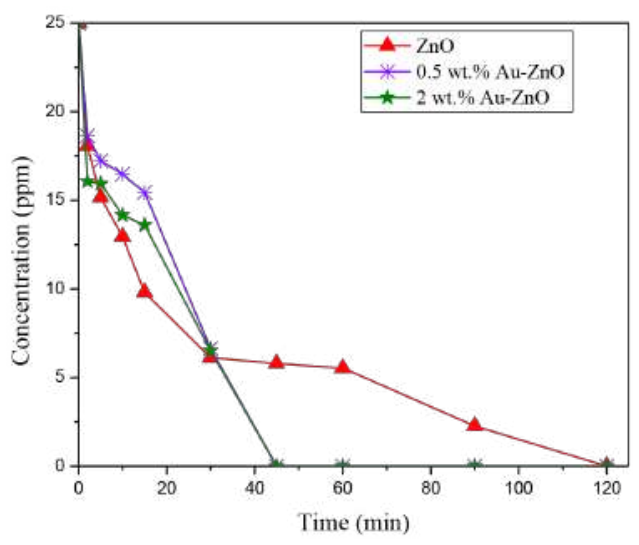

Figure 9 Evolution of the Catechol concentration after photocatalytic reaction by using the materials analyzed 


\section{Hydroquinone photodegradation}

Hydroquinone is transformed into Catechol during the photocatalytic reactions evaluated, the evolution of this substrate concentration as a function of the reaction time is represented in Figure 10.

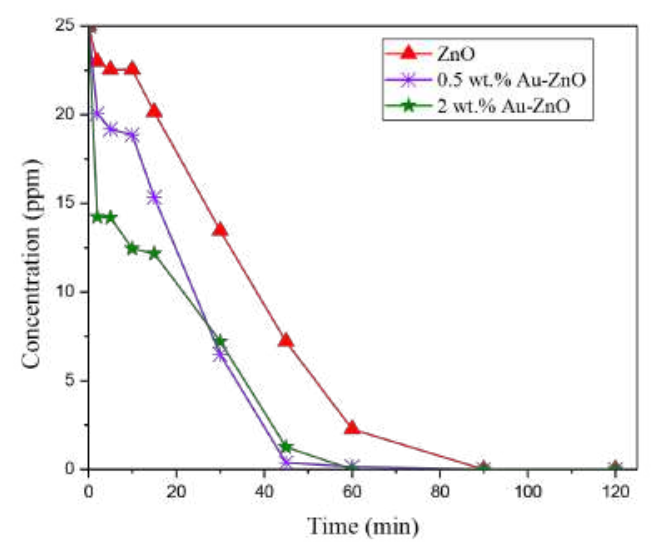

Figure 10 Evolution of the Hydroquinone concentration after photocatalytic reaction by using the materials analyzed

In this case, it is also observed that the gold addition is an important factor influencing the effectiveness of $\mathrm{ZnO}$ semiconductor in the photodegradation of this phenolic compound. It was found that the Hydroquinone reaction rate obtained over the $2 \mathrm{wt} . \% \mathrm{Au}-\mathrm{ZnO}$ photocatalyst is slightly higher than the obtained with the material prepared with the lowest gold content, i.e $7.13 \times 10^{-3}$ and $7.3 \times 10^{-3} \mathrm{mg}$ of hydroquinone. $\mathrm{L}^{-1} . \mathrm{s}^{-1}$, respectively.

The total reaction rate during the first $60 \mathrm{~min}$ of illumination was calculated in each photocatalytic test and the results obtained are presented in Table 1. As it can be seen in this table, the degradation rate for all the phenolic compounds analyzed increases with the addition of gold; thus, the lowest degradation rate was obtained over $\mathrm{ZnO}$ and the highest value for this parameter was observed by using $2 \mathrm{wt} . \% \mathrm{Au}-\mathrm{ZnO}$ as photocatalyst. These results are in good agreement, with the results observed when the phenolic compounds concentration was calculated. It was also observed that Catechol and Hydroquinone present higher degradation rate than Phenol, it can be due to the presence of two $\mathrm{OH}^{-}$groups in these compounds, the $\mathrm{O}-\mathrm{H}$ bond can be effectively broken leading to the transformation of Catechol and Hydroquinone; on the other hand, Phenol can be less reactive containing only one hydroxyl group in their molecular structure.

On the other hand, and taking into account that $\mathrm{TiO}_{2}$ has been considered as the typical reference semiconductor in photocatalysis, in this section, a commercial sample of Evonik P25 was tested in the degradation of the phenolic compounds, and it was observed that the efficiency of $\mathrm{TiO}_{2}$ in the phenolic compounds photodegradation is lower than the obtained with $\mathrm{ZnO}$ and $\mathrm{Au}-\mathrm{ZnO}$ photocatalyst, these degradation rate results have been included in Table 1.

It general, from the results obtained it can be concluded that the mechanism through the Phenol photodegradation carried out is similar to that previously reported [20], these authors have studied the phenol degradation by $\mathrm{TiO}_{2}$, in that work HPLC and GC-MS analyzes were performed and it was found that Phenol is transformed over Titania mainly in three intermediates, i.e Catechol, Hydroquinone and Resorcinol, other compounds also were detected.

In the present work, we employ $\mathrm{ZnO}$ as semiconductor, and it was observed that Phenol is transformed firstly in Catechol, then, this one is transformed in Hydroquinone and then Resorcinol is formed, other intermediates were not detected in the liquid phase during $120 \mathrm{~min}$ of photoreaction. It is possible that Resorcinol can be finally mineralized leading to $\mathrm{CO}_{2}$ and $\mathrm{H}_{2} \mathrm{O}$ formation.

It is also possible that similar to the reported by $\mathrm{TiO}_{2}$ also in the presence of $\mathrm{ZnO}$, the mechanism of the Phenol photodegradation takes place by $\bullet \mathrm{OH}$ radicals attack to phenyl ring, yielding Catechol, Resorcinol and Hydroquinone.

In the same vein, It is also important to note that Resorcinol was only detected during the Phenol photodegradation, in the case of Catechol or Hydroquinone degradation over $\mathrm{ZnO}$, this intermediate was not detected by HPLC. It was also observed that gold addition did not modify the proposal Phenol degradation route, in the reactions carried out by using Au-ZnO photocatalysts Resorcinol was not detected. On the other hand, during the Hydroquinone degradation over Au-ZnO only Catechol was detected; on the contrary, in the case of Catechol degradation, the presence of gold in the photocatalyst leads to the formation of two other intermediates different from Hydroquinone.

On the other hand, when Titania was employed as photocatalyst, the formation of five intermediates during the Phenol photodegradation was detected. Thus, in this case, it is possible that after phenolic compounds formation, the phenyl rings in these compounds break up to give short chain organic acids such as malonic acid, maleic, oxalic, acetic, formic, and finally $\mathrm{CO}_{2}$, as it was previously reported [20, 22, 23].

\section{Phenolic compounds mix}

In order to simulate a real industrial effluent, a $25 \mathrm{ppm}$ solution containing the three phenolic compounds (Phenol, Catechol and Hydroquinonel was prepared. Taking into account that the best photocatalytic performance in the individual phenolic compound degradation was observed by using $2 \mathrm{wt} . \% \mathrm{Au}-\mathrm{ZnO}$ as photocatalyst, this material was 
Table 1 Degradation rate of phenolic compounds over Au-ZnO photocatalysts

\begin{tabular}{c|cccc}
\hline & \multicolumn{4}{|c}{ Degradation rate (mg.L $^{-1} \cdot \mathbf{s}^{-1}$ ) } \\
\hline Phenolic compound & P25 & Zn0 & $\mathbf{0 . 5}$ wt.\%Au-Zn0 & wt.\%Au-Zn0 \\
\hline Phenol & $3.20 \times 10^{-3}$ & $3.50 \times 10^{-3}$ & $6.71 \times 10^{-3}$ & $6.90 \times 10^{-3}$ \\
Catechol & $3.98 \times 10^{-3}$ & $4.74 \times 10^{-3}$ & $7.70 \times 10^{-3}$ & $7.70 \times 10^{-3}$ \\
Hydroquinone & $3.92 \times 10^{-3}$ & $6.81 \times 10^{-3}$ & $7.13 \times 10^{-3}$ & $7.30 \times 10^{-3}$ \\
\hline
\end{tabular}

selected to test its effectiveness in the treatment of this solution. The results obtained are represented in Figure 11.

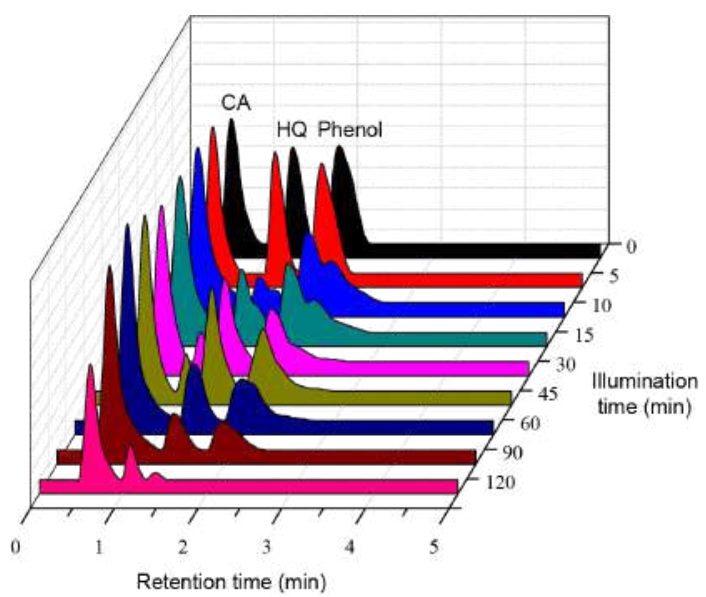

Figure 11 HPLC chromatograms for phenolic compounds mix photodegradation by using $2 \mathrm{wt} . \% \mathrm{Au}-\mathrm{ZnO}$ as photocatalyst

As it can be seen in Figure 11, after 10 minutes of illumination time, both, Phenol and hydroquinone start to be transformed in other compounds, which are evident due to the formation of two new signals in the chromatogram. In the case of the mix phenolic compounds photodegradation, it is observed that the effectiveness of the photocatalytic process is lower than the obtained in the tests performed with the phenolic substrates individually, thus, the total mineralization of these compounds was not achieved even after 120 min of photocatalytic treatment. This behavior is due to the simultaneous presence of three pollutants which can be transformed into others at the same time; in addition, these phenolic compounds can compete with each other by the hydroxyl radicals during the photocatalytic reaction, as it can be also explained by other authors [25]; this is one of the main challenge to deal when the photocatalytic processes are employed at big scale in the treatment of real wastewater polluted simultaneously with different organic and inorganic compounds.

\section{Conclusions}

$\mathrm{ZnO}$ semiconductor is an efficient material in the Phenol, Catechol and Hydroquinone photodegradation, this material has demonstrated to be more effective than commercial $\mathrm{TiO}_{2} \mathrm{P} 25$ in the treatment of these compounds in liquid phase.

Gold photodeposition is a suitable method to improve the $\mathrm{ZnO}$ photoactivity in the phenolic compounds degradation. The addition of this metal modifies the optical properties of this semiconductor mainly due to the color changes; it was also observed that metal loading is an important factor influencing the effectiveness of $\mathrm{ZnO}$, thus, the highest degradation rate of phenolic compounds was achieved by using the Au-ZnO photocatalyst prepared with $2 \mathrm{wt} . \%$ of gold content.

Phenol photodegradation mechanism depends on the catalyst employed in the photocatalytic reaction. Thus, over $\mathrm{ZnO}$ Phenol is mainly transformed in Catechol, Hydroquinone and Resorcinol, then the total mineralization of this compound is achieved. The Phenol degradation over $\mathrm{TiO}_{2}$ takes place in a longer reaction route by the formation of five compounds intermediaries before total mineralization.

Gold addition on $\mathrm{ZnO}$ did not modify the Phenol or Hydroquinone degradation mechanism observed with bare $\mathrm{ZnO}$. In the case of Catechol degradation over $\mathrm{Au}-\mathrm{ZnO}$, the presence of gold leads to the formation of two intermediates different from Hydroquinone.

\section{Acknowledgements}

This work was funded by Fondo Nacional de Financiamiento para la Ciencia, la Tecnología y la Innovación "Francisco José de Caldas", COLCIENCIAS (Project 279-2016) and Universidad Pedagógica y Tecnológica de Colombia.

\section{References}

[1] S. Ahmed, M. G. Rasul, W. N. Martens, R. Brown, and M. A. Hashi, "Heterogeneous photocatalytic degradation of phenols in wastewater: A review on current status and developments," Desalination, vol. 261, no. 1-2, pp. 3-18, Oct. 2010.

[2] P. Calza, D. Vione, and C. Minero, "The role of humic and fulvic acids in the phototransformation of phenolic compounds in seawater," Sci. Total Environ., vol. 493, pp. 411-418, Sep. 2014. 
[3] Y. Piña and et al., "Photocatalytic activity of $\mathrm{Al}_{2} \mathrm{O}_{3}$ improved by the addition of $\mathrm{Ce}^{3+} / \mathrm{Ce}^{4+}$ synthesized by the sol-gel method. photodegradation of phenolic compounds using UV light," Fuel, vol. 198, pp. 11-21, Jun. 2017.

[4] N. H. Salah, M. Bouhelassa, S. Bekkouche, and A. Boultii, "A study of photocatalytic degradation of phenol," Desalination, vol. 166, pp. 347-354, Aug. 2004.

[5] L. F. Velasco and et al., "Carbon foams as catalyst supports for phenol photodegradation," J. Hazard. Mater., vol. 184, no. 1-3, pp. 843-848, Dec. 2010.

[6] A. Tolosana, J. A. Anderson, J. A. Casas, M. Faraldos, and A. Bahamonde, "Defining the role of substituents on adsorption and photocatalytic degradation of phenolic compounds," J. Environ. Chem. Eng., vol. 5, no. 5, pp. 4612-4620, Oct. 2017.

[7] M. C. Hidalgo, J. J. Murcia, J. A. Navío, and G. Colón, "Photodeposition of gold on titanium dioxide for photocatalytic phenol oxidation," Appl. Catal., A, vol. 397, no. 1-2, pp. 112-120, Apr. 2011.

[8] D. Monllor and R. Gómez, "A photoelectrochemical and spectroscopic study of phenol and catechol oxidation on titanium dioxide nanoporous electrodes," Electrochim. Acta, vol. 55, no. 15, pp. 4661-4668, Jun. 2010.

[9] J. Tashkhourian, M. Daneshi, F. Nami, M. Behbahani, and A. Bagheri, "Simultaneous determination of hydroquinone and catechol at gold nanoparticles mesoporous silica modified carbon paste electrode," J. Hazard. Mater., vol. 318, pp. 117-124, Nov. 2016.

[10] M. Su, P. Chen, Y. Dong, and H. Sun, "Chemiluminescence of graphene quantum dots induced by acidic potassium permanganate and its application to quenchometric flow-injection assays of hydroquinone in water," J. Lumin., vol. 177, pp. 204-208, Sep. 2016.

[11] S. Jeenpadiphat, I. Mongkolpichayarak, and D. N. Tungasmita, "Catechol production from lignin by al-doped mesoporous silica catalytic cracking," J. Anal. Appl. Pyrolysis., vol. 121, pp. 318-328, Sep. 2016.

[12] J. J. Murcia and et al., "Methylene blue degradation over $\mathrm{M}-\mathrm{TiO}_{2}$ photocatalysts ( $\mathrm{M}=\mathrm{Au}$ or Pt)," Ciencia en Desarrollo, vol. 8, no. 1, pp. 109-117, Jan. 2017.

[13] C. Jaramillo, J. A. Navío, M. C. Hidalgo, and M. Macías, “High UV-photocatalytic activity of $\mathrm{ZnO}$ and $\mathrm{Ag} / \mathrm{ZnO}$ synthesized by a facile method," Catal. Today, vol. 284, pp. 121-128, Apr. 2017.

[14] V. Vaiano and et al., "Enhanced photocatalytic removal of phenol from aqueous solutions using $\mathrm{ZnO}$ modified with Ag," Appl. Catal., B., vol. 255, pp. 197-206, Jun. 2018.

[15] G. Ahmed and et al., "Defect engineering of $\mathrm{ZnO}$ nanoparticles by graphene oxide leading to enhanced visible light photocatalysis," $J$. Mol. Catal. A: Chem., vol. 425, pp. 310-321, Dec. 2016.

[16] E. Friehs and et al., "Toxicity, phototoxicity and biocidal activity of nanoparticles employed in photocatalysis," J. Photochem. Photobiol. C., vol. 29, pp. 1-28, Dec. 2016.

[17] P. Georgiev and et al., "Effect of gold nanoparticles on the photocatalytic efficiency of $\mathrm{ZnO}$ films," Colloids Surf., A., vol. 460, pp. 240-247, Oct. 2014.

[18] M. M. Hasan and R. K. Srivastava, "Structural, optical and photoconductivity study of $\mathrm{ZnO}$ nanoparticles synthesized by annealing of ZnS nanoparticles," J. Alloys Compd., vol. 691, pp. 275-286, Jan. 2017.

[19] C. G. Silva and et al., "Developing highly active photocatalysts: Gold-loaded ZnO for solar phenol oxidation," J. Catal., vol. 316, pp. 182-190, 2014.

[20] Z. Guo, R. Ma, and G. Li, "Degradation of phenol by nanomaterial $\mathrm{TiO}_{2}$ in wastewater," Chem. Eng. J., vol. 119, no. 1, pp. 55-59, Jun. 2006.

[21] K. Raja, P. S. Ramesh, and D. Geetha, "Structural, FTIR and photoluminescence studies of fe doped zno nanopowder by co-precipitation method," Spectrochim. Acta A. Mol. Biomol. Spectrosc., vol. 131, pp. 183-188, Oct. 2014.

[22] K. H. Wang, Y. H. Hsieh, M. Y. Chou, and C. Y. Chang, "Photocatalytic degradation of 2-chloro and 2-nitrophenol by titanium dioxide suspensions in aqueous solution," Appl. Catal. B., vol. 21, no. 1, pp. 1-8, May 1999.

[23] C. Wu, X. Liu, D. Wei, J. Fan, and L. Wang, "Photosonochemical degradation of phenol in water," Water Res., vol. 35, no. 16, pp. 3927-3933, Nov. 2001.

[24] S. Li, Z. Ma, J. Zhang, Y. Wu, and Y. Gong, "A comparative study of photocatalytic degradation of phenol of $\mathrm{TiO}_{2}$ and $\mathrm{ZnO}$ in the presence of manganese dioxides," Catal. Today, vol. 139, no. 1-2, pp. 109-112, Dec. 2008.

[25] C. Karunakaran and R. Dhanalakshmi, "Semiconductor-catalyzed degradation of phenols with sunlight," Sol. Energy Mater. Sol. Cells., vol. 92, no. 11, pp. 1315-1321, Nov. 2008. 